THURSDAY, JUNE IO, I 886

\section{THE 43-TON GUN EXPLOSION}

$\mathrm{T}^{\mathrm{H}}$ $\mathrm{HE}$ bursting of the 43-ton gun on board the Collingwood has naturally attracted considerable attention from men of science as well as from the general public, and it may not be out of place at the present time to compare the ideas of scientific men with the data given in text-books published by authority and put into the hands of artillery officers for purposes of instruction.

The latest gunnery text-book is that compiled by Major Mackinlay, R.A., and published in 1883 . In it is a table compiled by another artillery officer, in which is given the calculated and actual results obtained from all classes of ordnance, among them being the $12^{\prime \prime}$ B.L. gun of 43 tons, Mark II., the gun which burst on board the Collingwood.

The powder charge is given as $286 \mathrm{lbs}$. prismatic, projectile $720 \mathrm{lbs}$; the total work theoretically producible from the expansion of the charge in the bore 22,884 foot tons; the actual work produced in muzzle energy of projectile 17,180 foot tons. There is therefore, according to the table, a loss of 5704 foot tons to be expendedexternally in expelling the powder gases, displacing the atmosphere, and recoil ; internally in heating and stretching the gun, in friction of the gas check and gases, and rotating the shot.

In a lecture delivered in January $\mathrm{I} 885$, just after the bursting of the Active's 6" gun, Mr. Wm. Anderson pointed out that the lost work was very much greater than was usually imagined, and he went through a calculation on thermo-dynamical principles of the forces produced in a IO" B.L. gun. Taking Mr. Anderson's formulæ and adapting them to the I $2^{\prime \prime}$ B.L. gun, we shall not have to proceed far before finding out how erroneous is the table given in the text-book. We will only examine the forces external to the gun (i.e. those producing recoil), as $\mathrm{Mr}$. Anderson's accuracy on these points has been indorsed by Col. Moncrieff, C.B., F.R.S., and we shall neglect internal forces employed in friction stretching and heating the gun-forces difficult to estimate, and on which there is some difference of opinion.

As to the energy of the projectile there can be no question, but taking the terminal pressure at 3 tons (we believe it has risen as high as 5.5 to 6 tons) the energy of the expelled gases is 12,208 foot tons, that expended in lifting the atmosphere 250I tons, together 14,714 foot tons; so that, neglecting internal forces altogether-and these are no small quantity-we have 14,7 I4 foot tons of energy against 5704 in the text-book.

We can only conclude that the pressure corresponding to this difference, as well as that due to the forces expended inside the bore, have been entirely neglected by the designers of the guns.

The powder with which the gun was burst was that known as "cocoa"; this powder, while diminishing the maximum pressure carries it further down the bore (a most dangerous thing for guns weak in the chase), and increases the mean and final pressures, and the muzzle velocity; therefore the calculation we have given is VoL, XXXIV.-NO. 867 probably within the mark for an equal weight of cocoa powder.

The reason for the errors we have pointed out may probably be found in the blind confidence placed in the indications of crusher gauges. It is well known that a certain length of time must be taken up in the compression of all metals, and it is extremely doubtful whether something near the two-hundredth part of a second in which the explosion takes place is sufficient for the compression of copper cylinders, especially when comparisons are made between those near the breech, which are longer under the influence of the powder gases, and those in the muzzle, which are not acted on for any appreciable time.

The only item in the above estimates which has been ascertained by experiment is the muzzle velocity, the others are the result of calculation, and although Col. Moncrieff tells us they are to be trusted when measured in recoil, it would be far more satisfactory were they ascertained by direct experiment.

Means for verification have been pointed out, and although we believe the Government is provided with the instruments nothing has yet been done with them.

The failure of the Collingwood's gun raised hopes in the minds of many that at last a proper inquiry into the question would be held; but it has been referred back to the same Committee, associated with the same civilians (except Mr. Leece, who is dead), who recommended that the gun "should remain unaltered," but that " the charge of 295 lbs. of cocoa powder should not be exceeded."

They therefore are to sit in judgment on themselves, and if they relied on the same data when recommending certain additional strength should be given to other guns, as they did when merely limiting the charge of the $12^{\prime \prime}$, what reason is there for supposing that the results with other guns will differ from this one except in loss of life and damage done?

\section{GEOLOGY OF TURKESTAN}

Turkestan; a Geological and Orographical Description based upon Data collected during the Fourneys of 1874 to I880. By J. V. Moushketoff. Pp. 714. With Map and Engravings. Russian. (St. Petersburg, I886.)

FOR several years past all who take an interest in Central Asia have followed with great interest the yearly reports published by Profs. Romanovsky and Moushketoff on their geological explorations in the mountains of the Tian-Shan, the high plateaux of the Pamir, and the lowlands of the Amu-daria. The extensive character of these explorations, prosecuted for several consecutive years, and the practical experience of the two Russian geologists promised that new light would soon be thrown on several important but doubtful points in the geology of this most interesting region; but the appearance of their works has been delayed for some years. We have, however, now before us the first volume of M. Moushketoff's work, and when the whole, which will comprise three large volumes, as also M. Romanovsky's work on the same subject, is published, we shall have an almost complete picture of the geology of this region which contains the key to so many important geological questions in Europe. 